\title{
Safety and feasibility of percutaneous retrograde coronary sinus delivery of autologous bone marrow mononuclear cell transplantation in patients with chronic refractory angina
}

Jorge Tuma ${ }^{1}$, Roberto Fernández-Viña ${ }^{2}$, Antonio Carrasco ${ }^{3}$, Jorge Castillo ${ }^{3}$, Carlos Cruz ${ }^{1}$, Alvaro Carrillo ${ }^{1}$, Jose Ercilla ${ }^{1}$, Carlos Yarleque ${ }^{1}$, Jaime Cunza, Timothy D Henry ${ }^{4}$ and Amit N Patel ${ }^{5^{*}}$

\begin{abstract}
Background: Chronic refractory angina is a challenging clinical problem with limited treatment options. The results of early cardiovascular stem cell trials using ABMMC have been promising but have utilized intracoronary or intramyocardial delivery. The goal of the study was to evaluate the safety and early efficacy of autologous bone marrow derived mononuclear cells (ABMMC) delivered via percutaneous retrograde coronary sinus perfusion (PRCSP) to treat chronic refractory angina (CRA).

Methods: From May 2005 to October 2006, 14 patients, age 68 +/- 20 years old, with CRA and ischemic stress-induced myocardial segments assessed by SPECT received a median $8.19^{*} 10^{8} \pm 4.3^{*} 10^{8}$ mononuclear and $1.65^{*} 10^{7} \pm 1.42^{*} 10^{7}$ CD34 $4^{+}$cells by PRCSP..

Results: ABMMC delivery was successful in all patients with no arrhythmias, elevated cardiac enzymes or complications related to the delivery. All but one patient improved by at least one Canadian Cardiovascular Society class at 2 year follow-up compared to baseline $(p<0.001)$. The median baseline area of ischemic myocardium by SPECT of $38.2 \%$ was reduced to $26.5 \%$ at one year and $23.5 \%$ at two years $(p=0.001$ ). The median rest left ventricular ejection fraction by SPECT at baseline was 31.2\% and improved to $35.5 \%$ at 2 year follow up ( $p=0.019$ ). Conclusions: PRCSP should be considered as an alternative method of delivery for cell therapy with the ability to safely deliver large number of cells regardless of coronary anatomy, valvular disease or myocardial dysfunction. The clinical improvement in angina, myocardial perfusion and function in this phase 1 study is encouraging and needs to be confirmed in randomized placebo controlled trials.
\end{abstract}

\section{Background}

An increasing number of patients with coronary artery disease remain symptomatic with disabling angina despite the optimal use of antianginal medications and percutaneous or surgical revascularization $[1,2]$. Therapeutic angiogenesis is an experimental strategy utilizing angiogenic proteins, gene therapy or stem cells for inducing neovascularization of chronically ischemic myocardium $[3,4]$. Currently, the majority of clinical studies investigating autologous bone marrow mononuclear cells

\footnotetext{
* Correspondence: amit.patel@hsc.utah.edu

${ }^{5}$ University of Utah, Salt Lake City, UT, USA

Full list of author information is available at the end of the article
}

(ABMMC) transplantation as a treatment for ischemic myocardium have been performed in patients with acute myocardial infarction using intracoronary delivery [5-11]. In contrast, in patients with refractory ischemia only a few trials have been published and all have used intramyocardial delivery [12-16]. Percutaneous retrograde coronary sinus perfusion (PRCSP) is a well-established technique for delivery of cardioplegia solution in cardiovascular surgery and for protection against myocardial ischemia in patients undergoing high risk percutaneous coronary intervention (PCI) [17-19]. Delivery by PRCSP has been shown to be a reasonable alternative to intracoronary and intramyocardial delivery in preclinical 
therapeutic angiogenesis models using both angiogenic proteins, gene therapy and stem cell therapy [20]. The technique has the potential advantages of safety delivering a larger number of cells with more homogenious delivery across the myocardium to patients with refractory angina despite the presence of severe underlying coronary artery disease, valvular disease or previous myocardial infarction which may complicate delivery by either intracoronary or intramyocardial approach. The aim of the present study was to evaluate the safety of ABMMC delivered into the ischemic myocardium via PRCSP in patients with chronic refractory angina (CRA).

\section{Methods}

Patients

Patients with Canadian Cardiovascular Society (CCS) class III-IV angina despite maximal medical or surgical therapy who were ineligible for further percutaneous or surgical revascularization (based on coronary anatomy) and who had evidence for reversible ischemia on an exercise single photon emission computed tomography (SPECT) were enrolled. A committee comprising two cardiovascular surgeons and two interventional cardiologists determined the ineligibility for percutaneous or surgical revascularization. Patients with acute myocardial infarction, percutaneous or surgical revascularization within six months of enrollment in the study, a history of malignant disease, severe renal dysfunction, or unexplained hematology or biochemical abnormalities were excluded. The local ethics committee at Clinica Maison de Sante and Centro Cardiovascular San Nicolá $\mathrm{s}$ approved the protocol and all patients gave informed consent. The review and analysis of the data was also approved by the IRB at the University of Utah.

\section{Study protocol}

The baseline screening assessment of patients included clinical evaluation, electrocardiogram (ECG), laboratory evaluation (complete blood count, blood chemistry, erythrocyte sedimentation rate, creatine kinase, and troponin $\mathrm{T}$ serum levels). Patients kept a record of daily angina frequency for three weeks, and the severity of angina was graded according to the CCS class at baseline, 3,12 , and 24 months. Within two weeks prior to cell therapy, exercise capacity was evaluated using bicycle ergometry in conjunction with SPECT imaging to assess myocardial ischemia and left ventricular (LV) function.

\section{Periprocedural evaluation}

Patients had complete blood count, creatine kinase levels and ECG performed immediately prior to and immediate after the procedure. Complete blood count, creatine kinase, and troponin $\mathrm{T}$ levels were also assessed eight hours post procedure with an ECG prior to discharge. All patients were monitored in the cardiac intensive care unit for 12 hours after the procedure and were discharged the following day. A transthoracic echocardiogram was performed prior to discharge to detect the presence of pericardial effusion. The clinical follow-up evaluations including the laboratory tests described above were performed 3, 12 and 24 months after the injection procedure. At 12 and 24 months of follow-up exercise bicycle testing, and gated SPECT were performed.

\section{Assessment of exercise capacity}

All patients performed a symptom-limited bicycle exercise test with a $20-\mathrm{W}$ starting load and $10-\mathrm{W}$ increments per minute at baseline and at 12 and 24 months after the injection procedure. Antianginal medication was continued. The test points were angina pectoris, physical exhaustion, dyspnea, significant decrease in blood pressure $(10 \mathrm{mmHg})$, or achievement of maximal age-related heart rate. A 12-lead ECG was recorded before, during, and after the test. The total exercise duration, maximal workload achieved in percentages (expected for age, gender, height, and weigh) at baseline was compared to 12 and 24 months after ABMMC delivery.

\section{Single-photon emission computed tomography}

For the SPECT examination, a one-day rest-stress protocol was used. On the same day, images at rest were obtained 60 minutes after the ${ }^{99} \mathrm{~m}$ Technetium Sestamibi injection using a double-head SPECT camera as previously described. $(17,18)$ Using the bicycle exercise test, $99 \mathrm{~m}$ Technetium Sestamibi was injected intravenously at peak exercise ( $85 \%$ of the estimated heart rate) which was continued for 2 minutes after tracer injection and images were obtained 30 minutes after the stress test. Reconstruction yielded long-and short -axis projections perpendicular to the heart axis. The short-axis slices were displayed in polar map format.

\section{Bone marrow aspiration and isolation of mononuclear cells}

A volume of $300 \mathrm{ml}$ of bone marrow was harvested from the iliac crest under local anesthesia and placed in heparinized Hanks' balanced salt solution. ABMMC were isolated by Hess $6 \%$ density gradient centrifugation with a final suspension volume of $50 \mathrm{ml}$ and a mean cell concentration of $8.19^{*} 10^{8} \pm 4.3^{*} 10^{8}$ mononuclear cells and $1.65^{*} 10^{7} \pm 1.42^{*} 10^{7} \mathrm{CD} 34+$ cells.

\section{Delivery Procedure}

The femoral vein was cannulated with a 7 French sheath, a 6 French catheter was placed in the coronary sinus and a $0.035 \mathrm{~mm}$ hydrophilic guide wire was placed in the interventricular or lateral vein followed by placement of a peripheral balloon into the mid portion of the coronary sinus to allow nonselective delivery of cells. (Cook Medical, 
Indiana, USA). The balloon was inflated at very low pressure (1 to $2 \mathrm{~atm}$ ) for 10 minutes producing stagnation of the flow as previously described with infusion of the ABMMC. $(18,19) 50$ mls of ABMMC were injected manually through the balloon at a rate of $10 \mathrm{mls}$ per minute. The average total procedure time for cell delivery was 30 minutes.(Figure 1)

\section{Statistical analysis}

Data are reported as median \pm SDs. Quantitative data were compared using a paired, 2 tailed Student's test. Categorical data were compared using the Wilconxon signed rank test, a $\mathrm{p}<0.05$ was considered significant.

\section{Results}

The baseline clinical characteristics of the 14 enrolled RA patients are listed in Table 1. All patients had three vessel disease and were deemed ineligible for further revascularization by the screening committee of physicians. The patient's antianginal regimen was not changed during the 24 month follow-up.

\section{Safety assessment}

There was no evidence of inflammation or myocardial injury based on periprocedural laboratory evaluations (maximum erythrocyte sedimentation rate $20 \pm 12 \mathrm{~mm}$, maximum creatine kinase $137 \pm 68 \mathrm{U} / \mathrm{L}$, and maximum troponin T $0.010 \pm 0.019 \mathrm{ng} / \mathrm{mL}$ ) Ventricular arrhythmias were not observed during cell delivery or hospitalization and no patient had post procedural pericardial effusion by two-dimensional echocardiography before discharge. One patient died four months following the procedure due to liver cirrhosis, decompensated heart failure and pulmonary hypertension.

\section{Clinical outcomes}

The frequency of angina episodes per day decreased from $2.9 \pm 3.9$ at baseline to $1.0 \pm 1.4$ at 3 months ( $\mathrm{p}<$ $0.001), 0.7 \pm 1.2$ at 12 months $(\mathrm{p}<0.001)$ and $0.6 \pm 1.2$ at 24 months $(\mathrm{p}<0.001)$. Angina improved in $13 / 14$ patients and the mean Canadian Cardiovascular Society class improved from $3.2 \pm 0.6$ baseline to $1.9 \pm 0.7$ at 1 year $(\mathrm{p}<0.001)$ and $1.8 \pm 0.4$ at 2 years $(\mathrm{p}<0.001)$. The individual changes for anginal episodes per day for the 14 patients are shown in Figure 2.

\section{Exercise capacity}

At baseline, 14 patients had exercise duration time of $3.1 \pm 1.4$ minutes. This improved to $6.8 \pm 1.0$ and $7.4 \pm$ 1.7 minutes at 12 and 24 months of follow-up respectively, $(\mathrm{p}<0.001)$. The individual changes for exercise time are shown in Figure 3.

\section{Myocardial perfusion by SPECT}

The median percent of ischemic myocardium by SPECT was $38.2 \%$ at baseline and was reduced to $26.5 \%$ and $23.5 \%(\mathrm{p}=0.001)$ at 12 and 24 month follow-up (Table 2 and Figure 4). The number of segments with stress-inducible ischemia per patient improved $11.7 \%$ and $14.7 \%$ at 12 and 24 months of follow up. Examples of SPECT
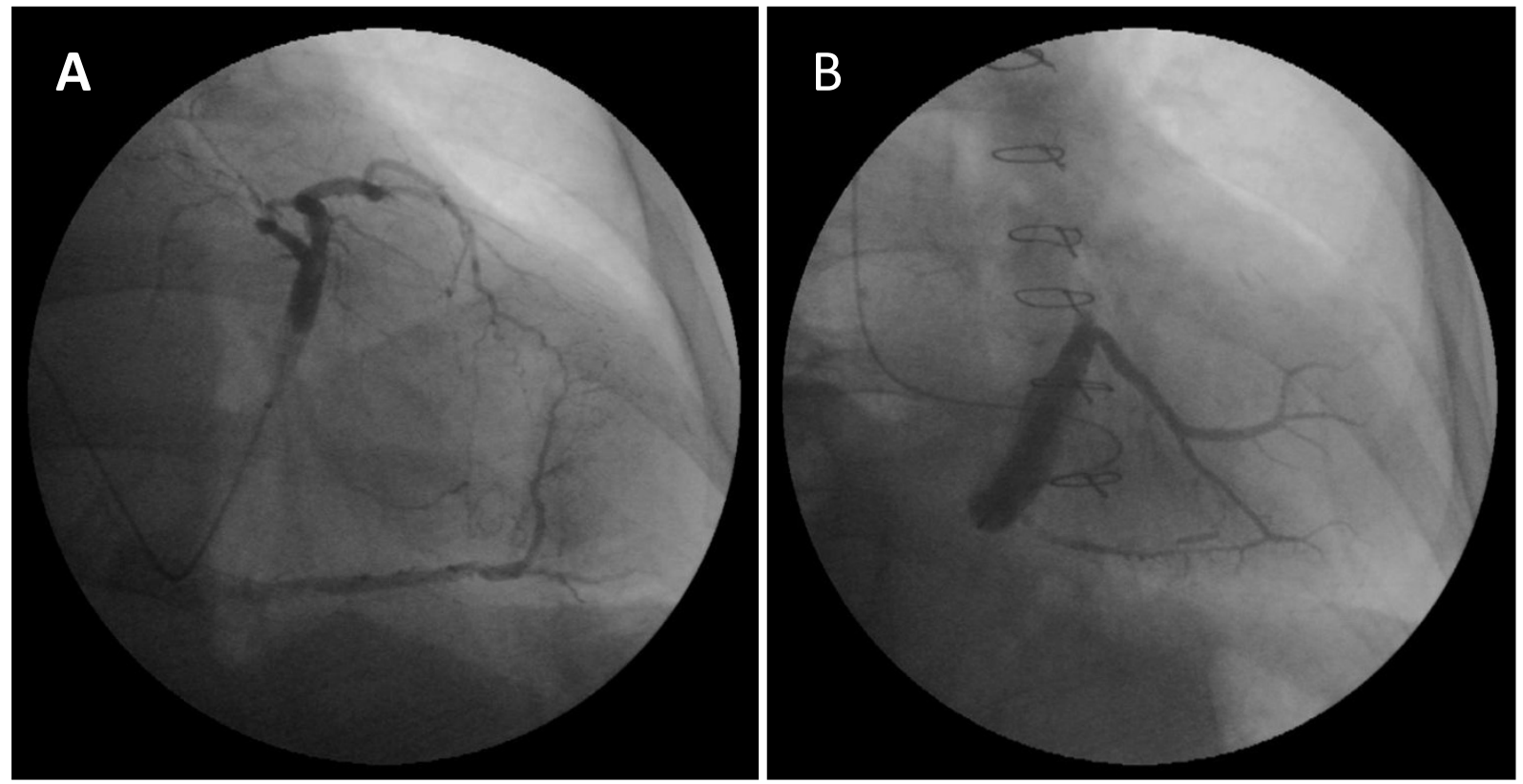

Figure $1 \mathrm{~A}$ : Unselected transplantation of BMC into the coronary veins, B: Selected transplantation of BMC into the lateral veins. 
Table 1 Baseline Clinical Demographics

\begin{tabular}{ll}
\hline Demographic & $\begin{array}{l}\text { ABMMC* } \\
\text { (N = 14) }\end{array}$ \\
\hline Median age & 68 \\
\hline Female/Male ratio & $1 / 6$ \\
\hline Systemic Hypertension - N (\%) & $14(100 \%)$ \\
\hline Hyperlipidemia - N (\%) & $12(85.7 \%)$ \\
\hline Diabetes Mellitus - N (\%) & $4(28.6 \%)$ \\
\hline Previous myocardial infarction - N (\%) & $14(100 \%)$ \\
\hline Previous percutaneous coronary intervention - N (\%) & $4(28.6 \%)$ \\
\hline Previous coronary artery bypass surgery - N (\%) & $9(64.3 \%)$ \\
\hline *ABMMC = autologous bone marrow mononuclear cells &
\end{tabular}

imaging of myocardial perfusion before and after ABMMC is shown for 2 patients in Figure $4 \mathrm{~A}$ and $4 \mathrm{~B}$ with improvements in both rest and stress perfusion.

\section{Function assessed by SPECT}

Median rest LV ejection fraction by SPECT at baseline was $31.2 \%$ and was improved to $35.4 \%$ and $35.5 \%$ at 12 and 24 month follow-up respectively $(\mathrm{p}<0.019)$. (Table 2 , Figure 5)

\section{Discussion}

This study demonstrates that ABMMC delivered by PRCSP in patients with CRA and stress-inducible ischemia was safe, may reduce anginal symptoms and improve exercise capacity. Stem cell transplantation by PRCSP is an alternative route of delivery to the myocardium for patients with coronary artery occlusion at their initial portions, or for patients with severe multivessel disease or occluded venous and arterial grafts. In this study we have demonstrated that, in patients with

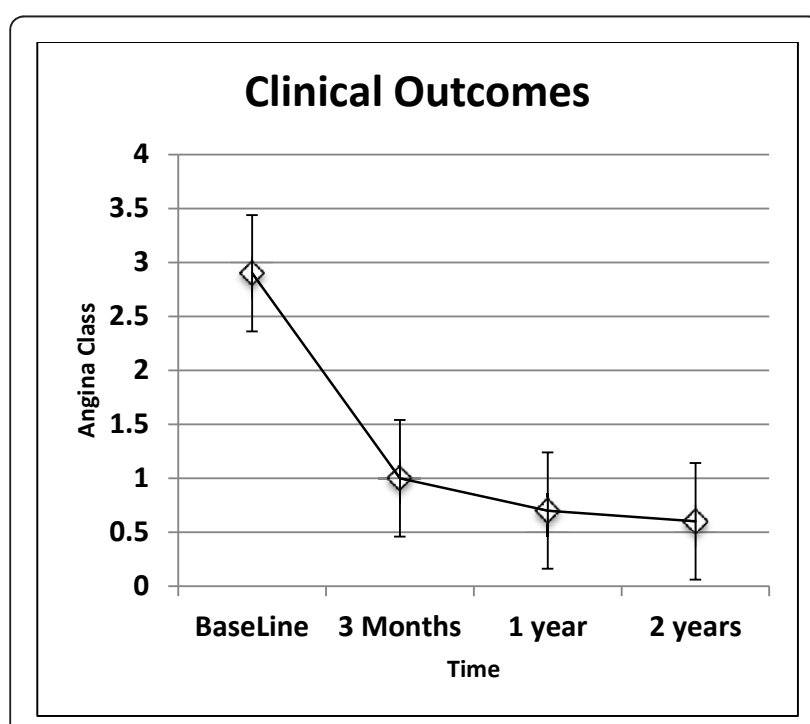

Figure 2 Clinical outcomes of angina class.

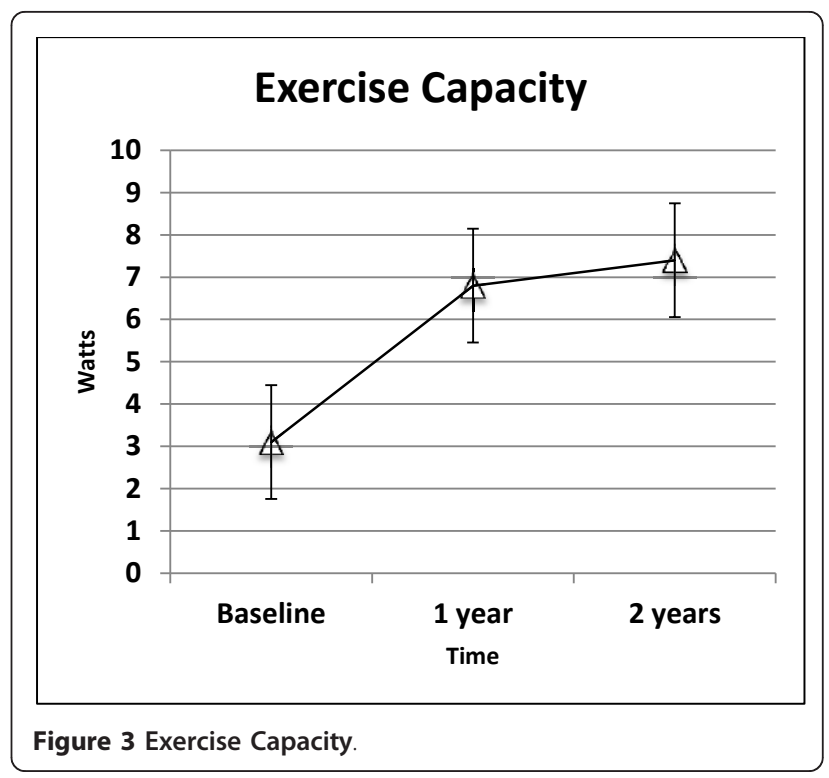

chronic ischemia with or without severely impaired LV function, that ABMMC injection enhances myocardial perfusion. In addition we observed that improved systolic LV function occurred only in patients with low ejection at baseline. Improvement and maintenance of the $\mathrm{LV}$ ejection fraction at 24 months follow-up was most likely a result of increased myocardial perfusion and global regional wall motion. This resulted in a reduced LV endsystolic volume. Consequently, the therapeutic effect appears to be more related to enhanced myocardial contractility rather than induction of LV reverse remodeling. The findings of the present study are consistent with the hypothesis that $\mathrm{ABMMC}$ promote angiogenesis, resulting in increased myocardial perfusion [18]. The present study was not designed to assess the underlying cellular mechanism of bone marrow cell injection improving myocardial perfusion and LV function. Therefore, secretion of proangiogenic factors by the bone marrow cells and differentiation of bone marrow cells in endothelium cells, smooth muscle cells, or cardiomyocytes could have contributed to the described effect. The mechanism of angiogenesis could be caused by differentiation of bone marrow cells in endothelial and/or vascular smooth muscle cells or by the production of angiogenic cytokines, as previously proposed but has not been fully validated [19]. ABMMC by the PRCSP has been proposed as a novel therapeutic option for patients with coronary artery disease. Until now most clinical studies investigating ABMMC were performed in patients with acute myocardial infarction. Data from patients with chronic ischemia are scarce. At present, only few studies in patients with chronic coronary artery disease have been published [9-13]. The current results are in line with studies on the safety and feasibility of intramyocardial delivery of ABMMC in patients with 
Table 2 Analysis pre and post ABMMC transplantation: Canadian Cardiovascular Society class, rest left ventricular ejection faction and ischemic myocardium percent

\begin{tabular}{lllll}
\hline & $\begin{array}{l}\text { BASELINE } \\
(\mathbf{N}=\mathbf{1 4})\end{array}$ & $\begin{array}{l}\mathbf{1} \text { YEAR } \\
(\mathbf{N}=\mathbf{1 3})\end{array}$ & $\begin{array}{l}\mathbf{2} \text { YEARS } \\
\mathbf{( N = 1 3 )}\end{array}$ & P value \\
\hline $\begin{array}{l}\text { REST Global LVEF* (\%) } \\
\text { Median }\end{array}$ & 31.2 & 35.4 & 35.5 & 0.019 \\
\hline CCS+ Median & 3 & 2 & 2 & $<0.001$ \\
\hline Ischemic Myocardium (\%) Median & 38.2 & 26.5 & 23.5 & 0.001 \\
\hline
\end{tabular}

*LVEF = left ventricular ejection fraction; +CCS = Canadian Cardiovascular Society
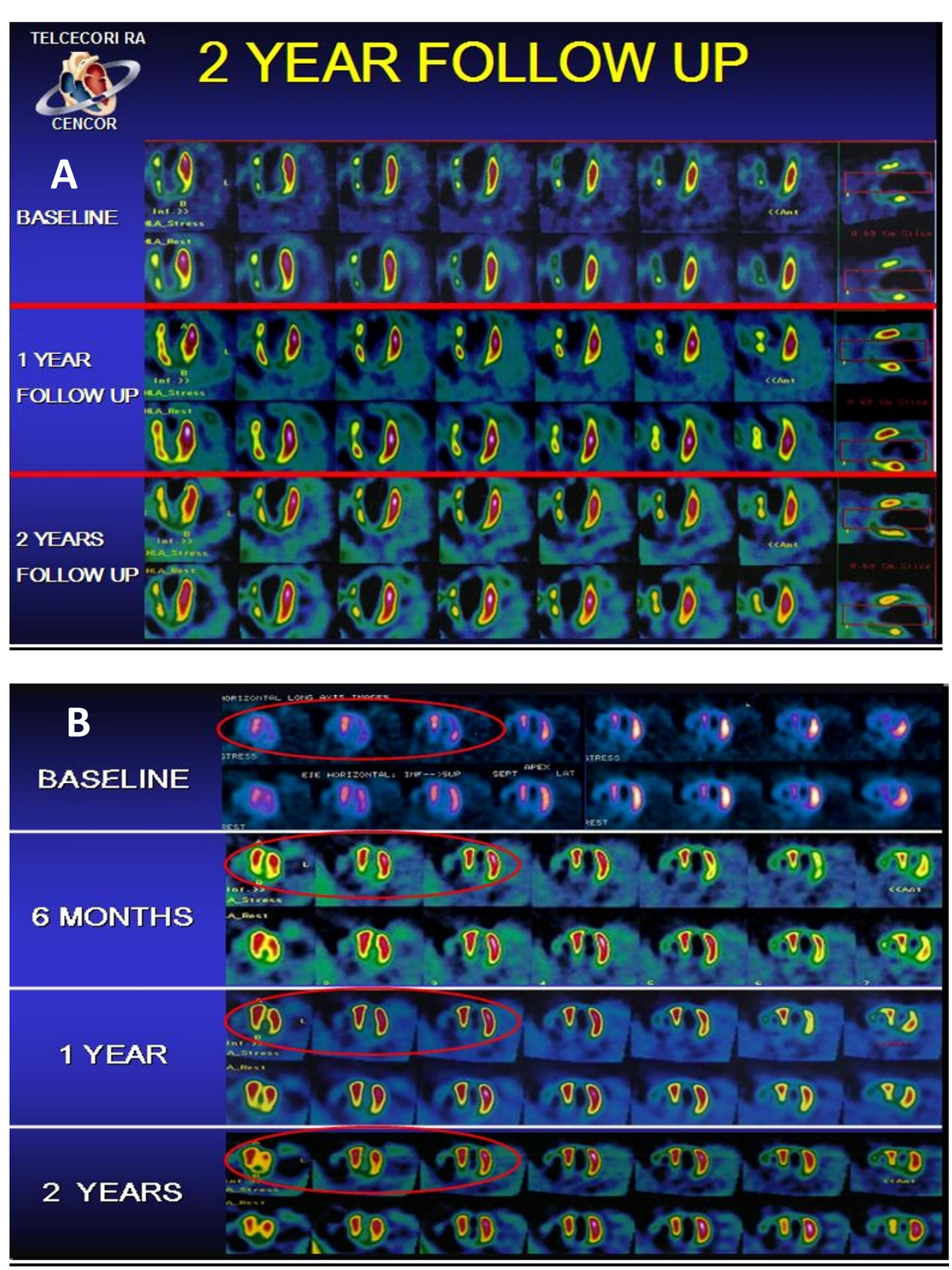

Figure 4 A: Perfusion imaging in a patient at 2 year follow up, B: Perfusion imaging in another patient at 2 year follow up. 


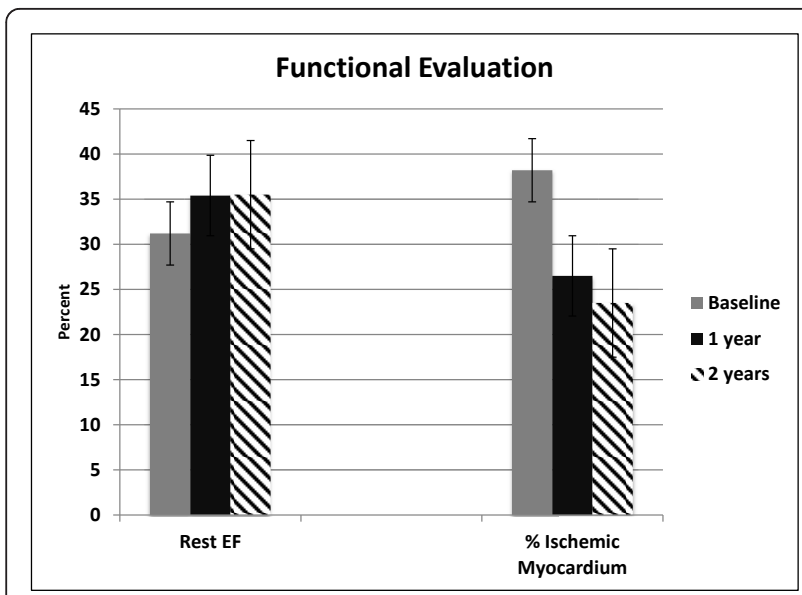

Figure 5 Functional evaluation of myocardium.

chronic ischemia and angina pectoris. Tse et al ${ }^{9}$ described a reduction in anginal symptoms, improved wall motion and improved wall thickening at 3 'months follow-up in 8 patients. In addition, the area of hypoperfused myocardium was reduced on SPECT. Fuchs et al reported a reduction in anginal symptoms and improved myocardial perfusion in 27 patients with a trend toward improved LV ejection fraction [11]. Perin et al reported the same results in 21 patients [12]. In a randomized controlled study Losordo et al demonstrated data that CD34 + after GCSF can be safely transplanted via intramyocardial injection and may improve perfusion and reduce symptoms in patients with advanced coronary disease [14]. In this pilot trial ABMMC were successfully delivered in each patient without any major periprocedural events (i.e., death, myocardial infarction, ventricular arrhythmias, cardiac perforation, pericardial effusion or significant enzyme release) using PRCSP. The present study supports previously suggested beneficial effects in preclinical models of retrograde stem cells delivery for cardiac disease, $[21,22]$ and the first to demonstrate improvement on symptoms, perfusion defects and LV function by PRVST in patients with preserved or decreased LV ejection fraction. However, we found similar improvements in patients with chronic ischemia with or without severely impaired LV function. This study suggests improvement and potential outcome durability of angina symptoms relief and better angina class, myocardial perfusion and contractility with this therapeutic approach in chronic refractory angina patients. We believe there may be clinical potential for this relatively novel method of cell delivery for patients suffering from refractory angina. We currently have a number of clinical trials using retrograde delivery of cells for both chronic refractory angina and heart failure based on this trial. Larger randomized trials will be needed to determine optimal cell numbers and to further understand the clinical outcomes.

\section{Abbreviation List}

ABMMC: autologous bone marrow mononuclear cells; CCS: Canadian Cardiovascular Society; CRA: refractory angina; ECG: electrocardiogram; LV: left ventricular; PRCSP: percutaneous retrograde coronary sinus perfusion; SPECT: single photon emission computed tomography.

\section{Author details}

'Division of Interventional Cardiology and Regenerative Medicine, Clí nica Maisó n de Santé, Lima, Peru. ${ }^{2}$ Centro Cardiovascular San Nicolás, Don Roberto Fernandez-Viñ a Foundation, San Nicolas, Argentina. ${ }^{3}$ Instituto de Criopreservació n y Terapia Celular, Lima, Peru. ${ }^{4}$ Abbott Northwestern Hospital, Minneapolis, MN, USA. ${ }^{5}$ University of Utah, Salt Lake City, UT, USA.

\section{Authors' contributions}

JT, RFV, AC, JC, CC, AC, JE, CY, JC enrolled and treated the patients. JT, RFV, AP conceived the study. JT, TH, AP all help to draft the manuscript and were involved in the data analysis. All authors read and approved the final manuscript.

\section{Competing interests}

The authors declare that they have no competing interests.

Received: 24 September 2011 Accepted: 26 October 2011 Published: 26 October 2011

\section{References}

1. Jolicoeur EM, et al: Clinical and research issues regarding chronic advanced coronary artery disease part II: Trial design, outcomes, and regulatory issues. American heart journal 2008, 155(3):435-44.

2. Mannheimer $C$, et al: The problem of chronic refractory angina; report from the ESC Joint Study Group on the Treatment of Refractory Angina. European heart journal 2002, 23(5):355-70.

3. Strauer $B E$, et al: Repair of infarcted myocardium by autologous intracoronary mononuclear bone marrow cell transplantation in humans. Circulation 2002, 106(15):1913-8.

4. Wollert $\mathrm{KC}$, et al: Intracoronary autologous bone-marrow cell transfer after myocardial infarction: the BOOST randomised controlled clinical trial. Lancet 2004, 364(9429):141-8.

5. Schachinger $V$, et al: Transplantation of progenitor cells and regeneration enhancement in acute myocardial infarction: final one-year results of the TOPCARE-AMI Trial. Journal of the American College of Cardiology 2004, 44(8):1690-9.

6. Chen SL, et al: Effect on left ventricular function of intracoronary transplantation of autologous bone marrow mesenchymal stem cell in patients with acute myocardial infarction. The American journal of cardiology 2004, 94(1):92-5.

7. Schachinger $V$, et al: Intracoronary bone marrow-derived progenitor cells in acute myocardial infarction. The New England journal of medicine 2006, 355(12):1210-21.

8. Janssens $S$, et al: Autologous bone marrow-derived stem-cell transfer in patients with ST-segment elevation myocardial infarction: double-blind, randomised controlled trial. Lancet 2006, 367(9505):113-21.

9. Lipinski MJ, et al: Impact of intracoronary cell therapy on left ventricular function in the setting of acute myocardial infarction: a collaborative systematic review and meta-analysis of controlled clinical trials. Journal of the American College of Cardiology 2007, 50(18):1761-7.

10. Tse HF, et al: Angiogenesis in ischaemic myocardium by intramyocardial autologous bone marrow mononuclear cell implantation. Lancet 2003, 361(9351):47-9.

11. Fuchs $\mathrm{S}$, et al: Catheter-based autologous bone marrow myocardial injection in no-option patients with advanced coronary artery disease: a feasibility study. Journal of the American College of Cardiology 2003, 41(10):1721-4.

12. Perin EC, et al: Transendocardial, autologous bone marrow cell transplantation for severe, chronic ischemic heart failure. Circulation 2003, 107(18):2294-302. 
13. Briguori $\mathrm{C}$, et al: Direct intramyocardial percutaneous delivery of autologous bone marrow in patients with refractory myocardial angina. American heart journal 2006, 151(3):674-80.

14. Losordo DW, et al: Intramyocardial, autologous CD34+ cell therapy for refractory angina. Circulation research 2011, 109(4):428-36.

15. Giordano FJ: Retrograde coronary perfusion: a superior route to deliver therapeutics to the heart?*. Journal of the American College of Cardiology 2003, 42(6):1129-31.

16. Boekstegers $P$, et al: Selective suction and pressure-regulated retroinfusion: an effective and safe approach to retrograde protection against myocardial ischemia in patients undergoing normal and high risk percutaneous transluminal coronary angioplasty. Journal of the American College of Cardiology 1998, 31(7):1525-33.

17. Pohl T, et al: Retroinfusion-supported stenting in high-risk patients for percutaneous intervention and bypass surgery: results of the prospective randomized myoprotect I study. Catheterization and cardiovascular interventions: official journal of the Society for Cardiac Angiography \& Interventions 2004, 62(3):323-30.

18. Raake $P$, et al: Myocardial gene transfer by selective pressure-regulated retroinfusion of coronary veins: comparison with surgical and percutaneous intramyocardial gene delivery. Journal of the American College of Cardiology 2004, 44(5):1124-9.

19. von Degenfeld $G$, et al: Selective pressure-regulated retroinfusion of fibroblast growth factor-2 into the coronary vein enhances regional myocardial blood flow and function in pigs with chronic myocardial ischemia. Journal of the American College of Cardiology 2003, 42(6):1120-8.

20. Hoshino $\mathrm{K}$, et al: Three catheter-based strategies for cardiac delivery of therapeutic gelatin microspheres. Gene therapy 2006, 13(18):1320-7.

21. Hou D, et al: Radiolabeled cell distribution after intramyocardial, intracoronary, and interstitial retrograde coronary venous delivery: implications for current clinical trials. Circulation 2005, 112(9 Suppl):1150-6.

22. George JC, et al: Transvenous intramyocardial cellular delivery increases retention in comparison to intracoronary delivery in a porcine model of acute myocardial infarction. Journal of interventional cardiology 2008, 21(5):424-31.

doi:10.1186/1479-5876-9-183

Cite this article as: Tuma et al: Safety and feasibility of percutaneous retrograde coronary sinus delivery of autologous bone marrow mononuclear cell transplantation in patients with chronic refractory angina. Journal of Translational Medicine 2011 9:183.

\section{Submit your next manuscript to BioMed Central and take full advantage of:}

- Convenient online submission

- Thorough peer review

- No space constraints or color figure charges

- Immediate publication on acceptance

- Inclusion in PubMed, CAS, Scopus and Google Scholar

- Research which is freely available for redistribution

Submit your manuscript at www.biomedcentral.com/submit
Biomed Central 